\title{
Stress analysis of micro drills based on FEA
}

\author{
Yanhong Sun and Yaxin Cui ${ }^{\mathrm{a}}$ \\ College of Mechanical Engineering, Jilin Engineering Normal University, Changchun, China
}

\begin{abstract}
Many cutting errors cause micro drills breakage in a kind of complex stress state under loaded by thrust, torque and radial force. It is important to research the breakage mechanism of micro drills and prevent from breakage during micro drilling. In this paper, a 3D micro drill is modeled by using the Pro-Engineer software. The maximum load and the stress distribution are calculated by using MSC.FEA software, which is a kind of finite element analysis(Abbreviated as FEA)method. The fracture mechanism of micro drill with different diameter under one or more loads is discussed, and the maximum axial force and maximum torque of the micro drill bit under the complicated working condition are obtained. A large number of experimental results can be used for practical engineering reference.
\end{abstract}

Keywords: micro drills; drill stresses; 3D model; FEA.

\section{Introduction}

In current manufacturing industry, many miniature machine parts and apparatus ne75ed more and more micro holes with the diameter of less than $1 \mathrm{~mm}$. A economical and useful method to machining micro holes is usual using the twist drills (micro drilling)[1]. A boring problem during micro drilling is easy breakage of micro drills, the common causes of failure of micro drills are that the drilling thrust or torque increases along with micro drills wear, finally exceeds its strength limit[2], or micro drills occur excessive twisting or bending, i.e. excessive shear stress or bending stress[3]. Therefore how to avoid micro drills breakage has been a difficult technical problem.

In this work, a drilling model was developed, and the stress analysises and the stiffness calculations were finished with the MSC.FEA software using the FEA method. These works may provide some useful references for preventing from the micro drill breakage.

\section{Strength models of micro drills}

A drilling system principle model is developed, in which a micro drill is regarded as a connection with two equal section beams, the upper is the clamped part of micro drill, the lower half is the spiral of micro drill. There are some inevitable errors, for example asymmetrical structure of micro drills, deflection of micro drills at the entrance, machine tool vibration during micro drilling, and so on. So micro drills are carried three kinds of forces including thrust, torque and radial force (refer with: Fig.1), Where $F$ is the thrust, $P_{r}$ is the radial force, $M_{n}$ is the torque, $l_{1}$ is the spiral length, $l$ is the body length.

a Corresponding author : 343175460@qq.com 
The stress concepts from "Material Mechanics" [4] will be applied in this paper. The stress analyses of the simplified micro drill as a cylinder are shown in Fig.2. Micro drills are in a compounding stress state which has the compress stress $\sigma^{\prime}$, the shear stress $\tau_{n}$, the bending stress $\sigma^{\prime \prime}$ and $\sigma_{r}[5]$.

\section{Simulation calculation of micro drills}

\subsection{Development of 3Ddrill model}

A 3D micro drill model is manufactured with the Pro-Engineer software, and is imported into the MSC.FEA software. Finally, the model is developed using the finite element (shortening is FE) model, the loading model, and the corresponding boundary conditions [6]. The geometric features considered of the $0.4 \mathrm{~mm}$ micro drill is shown in Table 1[7], Fig.3 shows its3D solid model. This model almost possesses all characters of the practical micro drill, so the calculation results on this FE model should be reliable.

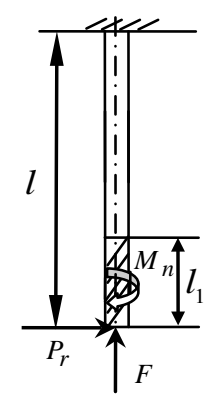

Figure 1. Micro drill model

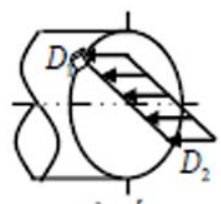

a) $\sigma^{\prime}$

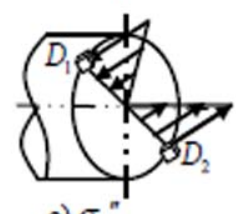

c) $\sigma$

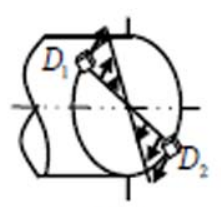

b) $\tau_{n}$

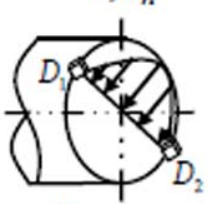

d) $\sigma_{\tau}$

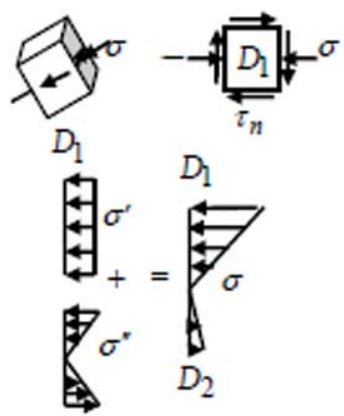

e) Limited stress

Figure 2. Stress analysis
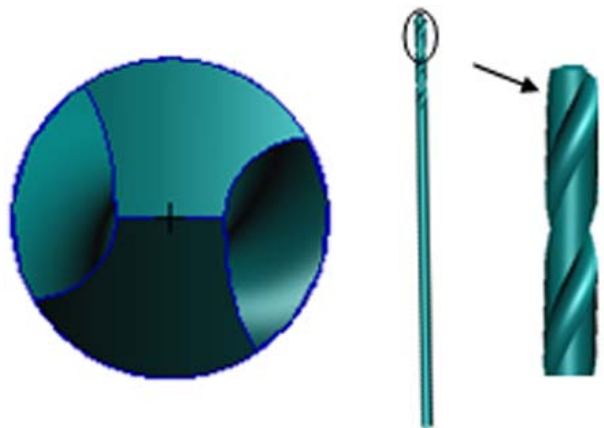

Figure 3. 3D drill model

Table1. Geometric features of micro drill

\begin{tabular}{lclc}
\hline Structure parameter & value & Structure parameter & value \\
\hline Diameter $(\mathrm{mm})$ & 0.4 & Point angle $\left(^{\circ}\right)$ & 118 \\
Body length $(\mathrm{mm})$ & 20 & Chisel edge angle $\left({ }^{\circ}\right)$ & 55 \\
Spiral length $(\mathrm{mm})$ & 5 & Spiral angle $\left(^{\circ}\right)$ & 29 \\
Web thickness $(\mathrm{mm})$ & 0.126 & & \\
\hline
\end{tabular}




\subsection{Determination of the maximum load}

The $0.3 \mathrm{~mm} \sim 0.6 \mathrm{~mm}$ HSS drills are used to calculate the maximum loading forces with the MSC.FEA software. The extending length is $9 \mathrm{~mm}$, the allowable compress and bending stresses of $\operatorname{HSS}[\sigma]$ is $1400 \mathrm{MPa}$, the allowable shear stresses of $\operatorname{HSS}[\tau]$ is $920 \mathrm{MPa}$, while $n_{s}$ is 2.5[4]. The simulative results are shown in Table 2 and Table3. Fig. 4 shows the maximum simulative stress distributions of a $\varnothing 0.4 \mathrm{~mm}$ micro drill.

Table2. Calculating results under single force

\begin{tabular}{llllll}
\hline$D(\mathrm{~mm})$ & & 0.3 & 0.4 & 0.5 & 0.6 \\
\hline \multirow{2}{*}{ maximum thrust $(\mathrm{N})$} & simulative value & 61 & 103 & 168 & 238 \\
& Principal value & 66.5 & 115.3 & 176.8 & 253.3 \\
maximum torque( N.mm $)$ & simulative value & 2.4 & 5.8 & 10.5 & 18.6 \\
& principal value & 2.64 & 6.14 & 11.56 & 19.97 \\
\hline
\end{tabular}

Table3. Calculating results under compounding forces

\begin{tabular}{llllll}
\hline$D(\mathrm{~mm})$ & & 0.3 & 0.4 & 0.5 & 0.6 \\
\hline radial force(mN) & & 150 & 150 & 150 & 150 \\
maximum thrust $(\mathrm{N})$ & simulative value & 41 & 85 & 149 & 220 \\
& principal value & 46.4 & 87.9 & 157.9 & 235.8 \\
\multirow{2}{*}{ maximum torque(N.mm) } & simulative value & 1.95 & 5.00 & 9.25 & 16.8 \\
& principal value & 2.22 & 5.32 & 10.10 & 18.18 \\
\hline
\end{tabular}

\section{Result analysis}

\subsection{Discussion of breakage mechanism of micro drills}

These result pictures show that there are high stress concentrations occurring along the cutting fringe, chisel edge and spiral root of micro drills. Micro drills would break off while the stresses exceed their limits. There are mostly four breakage modes for micro drills because of lower strength and rigidity. First is the drill tip ripped off since higher stress concentration existing along the chisel edge in micro drilling; Second is the spiral twisted off since the spiral's cross section area is too small and its strength is great low for a torque applied at the spiral fringe; Third is the spiral crushed off since much compress stress than the clamp for too great a thrust applied at the drill cutting edge; Fourth is the spiral root or the clamp root broken off because of the excessive bending stress concentration caused by too great the bending moments and too low the rigidity. The analysis results may be confirmed by the breakpoint pictures shown in Fig.5.

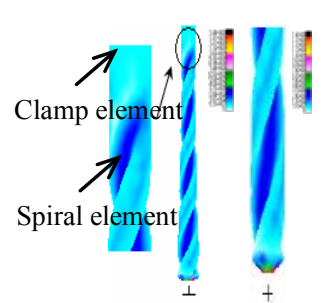

(a) Compress stress

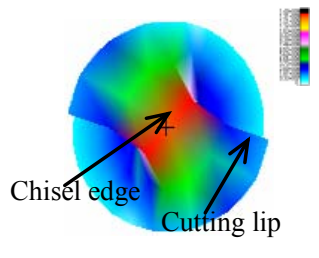

(b) Shear stress 


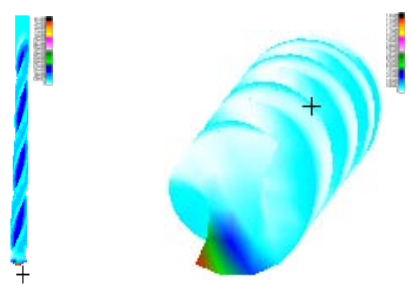

(c) Compress-bending stress

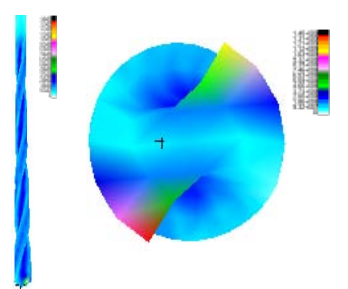

(d) Twist-bending stress

Figure 4. Maximum stress distributions of micro drills

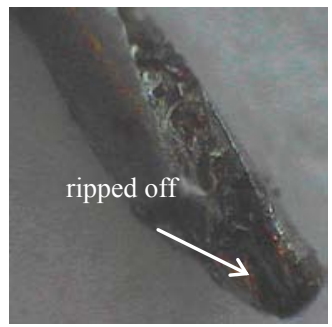

(a) Ripped off

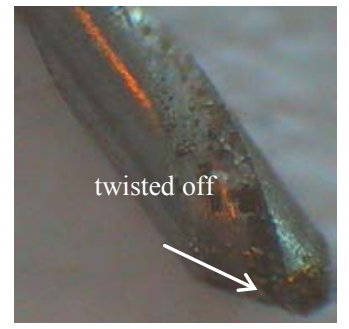

(b) Twisted off

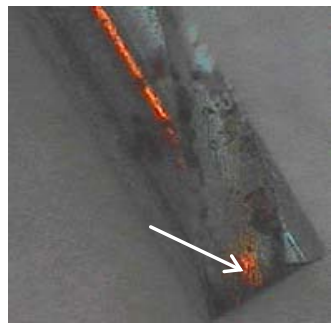

(c)Crushed off

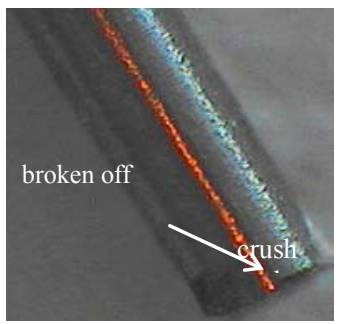

(d)Broken off

Figure 5. Typical breakpoint pictures from many experiments

\subsection{Analysis of maximum loading forces}

For easy to analyze the trends of the maximum loading forces, the results on Table 2 and Table 3 are plotted and shown in Fig.6. The plots indicate that maximum thrust and torque rise nonlinear along with the diameters of micro drills increasing, and improve markedly in speed as the diameter beyond $0.4 \mathrm{~mm}$, for instance, the rising ratios for the maximum thrust and torque are higher among between $0.4 \mathrm{~mm}$ to $0.5 \mathrm{~mm}$ or $0.5 \mathrm{~mm}$ to $0.6 \mathrm{~mm}$ than between $0.3 \mathrm{~mm}$ to $0.4 \mathrm{~mm}$, that is the inner stresses in micro drills have much more sensitive to the diameter beyond $0.4 \mathrm{~mm}$ under the calculating conditions of this work.

The second indication from the plots is the inner stresses in micro drills rising greatly along the radial force on micro drills. Under the same diameter, the maximum loading forces decrease while micro drills loaded the radial force. For instance, the reducing ratio of maximum thrust is $16 \%$, and the reducing ratio of maximum torque is $13 \%$ for the $\varnothing 0.4 \mathrm{~mm}$ micro drill loaded the $150 \mathrm{mN}$ radial force.

\subsection{Error analysis}

The contrasted results between the principal values and the simulative values are shown in Fig.7. Their changing trend are alike, the errors between principal values and simulative values are little. It is obvious that the model of microdrills as the connection with two section beams is feasible. 


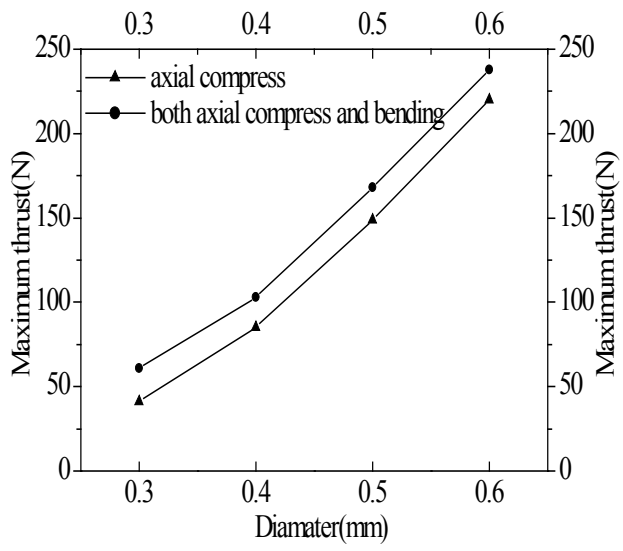

(a) Thrust curve

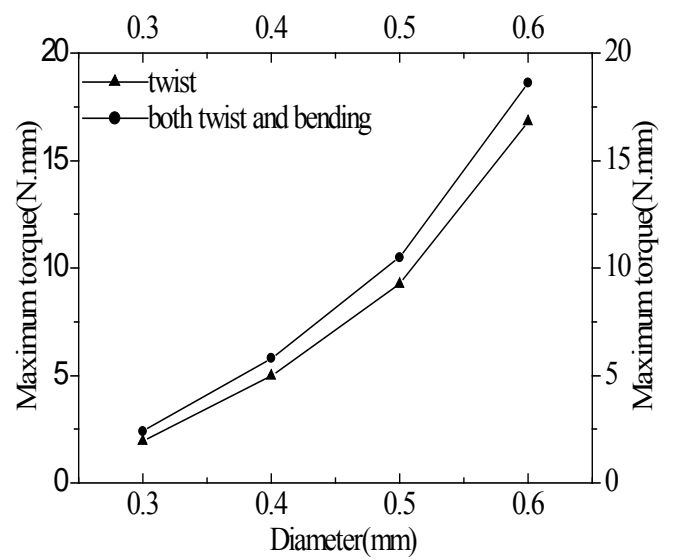

(b) Torque curve

Figure 6. Resultant forces with different drill diameters

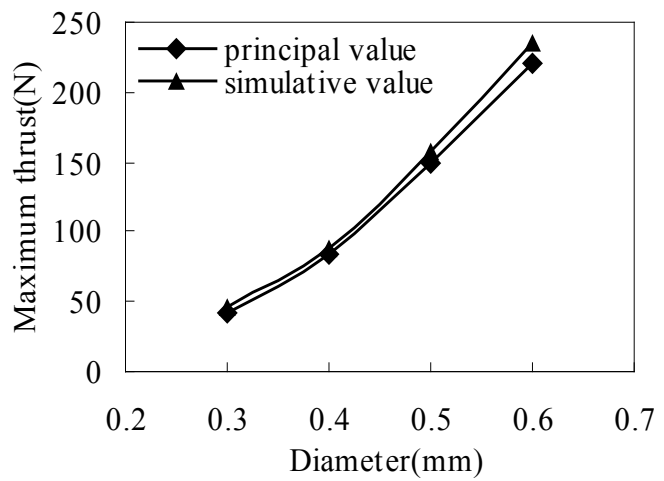

(a) Thrust curve

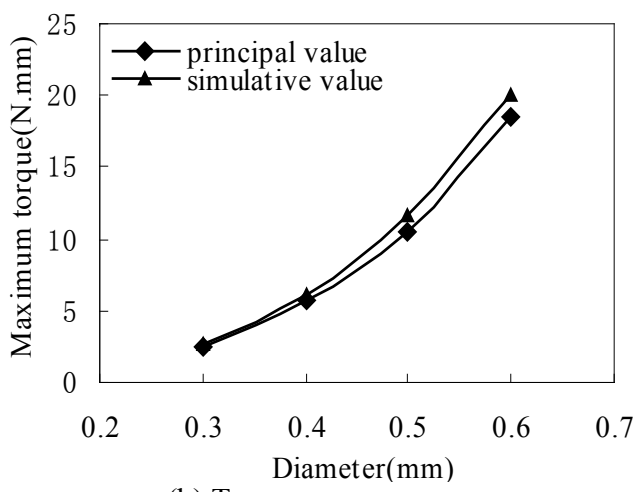

(b) Torque curve

Figure 7. Contrast plots for forces

\section{Experiment validation}

In order to confirm the results of FEA, an experiment investigation is conducted. The system's structure drawing is shown in Fig. 8 . The $\varnothing 0.4 \mathrm{~mm}$ micro drills are used until breakage. The thrust and torque signals are monitored during drilling. One experimental results are shown in Fig.9, coming from these cutting conditions, which the micro drill's diameter is $0.4 \mathrm{~mm}$, the work piece material is the $1 \mathrm{Cr} 18 \mathrm{Ni} 9$ stainless steel, the spindle speed of the drill is $15000 \mathrm{r} / \mathrm{min}$ and its feed speed is $4.0 \mathrm{~mm} / \mathrm{min}$. 


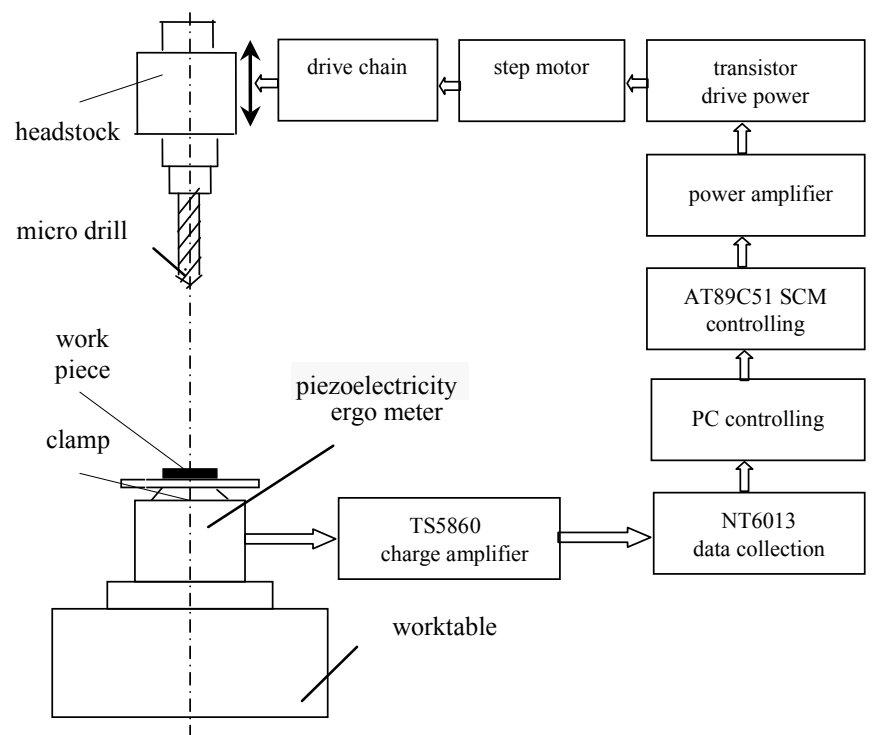

Figure 8. Structure drawing of the experiment system

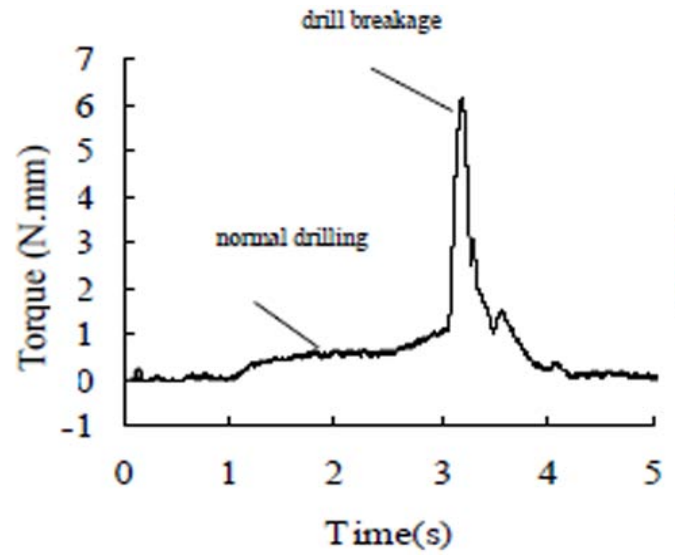

(a) Torque curve

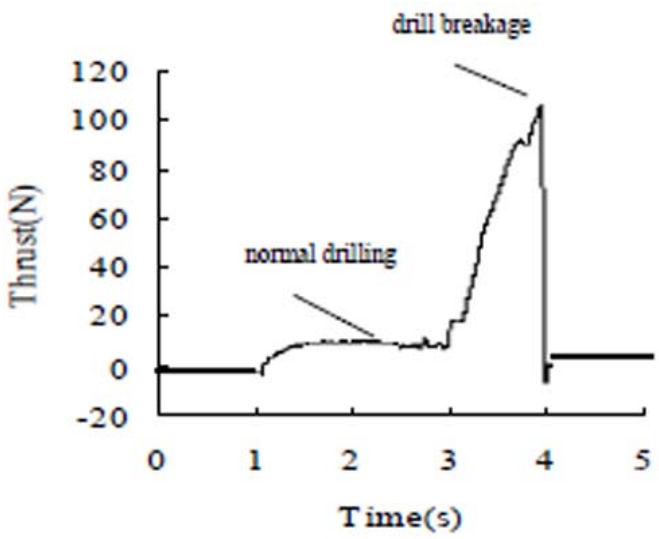

(b) Thrust curve

Figure 9. Drilling forces signals of micro drills from experiments

Alike to those indicated earlier in principle or simulation, the maximum thrust is close to $110 \mathrm{~N}$, the maximum torque is close to $6 \mathrm{~N} . \mathrm{mm}$. The experimental results indicate that it is credible to carry the values of thrust and torque on micro drills by using FEA method in this work, the thrust and torque may be as the monitoring signals to forecast the micro drills' wear state [8]. The calculated values may be regarded as the reference monitoring limens of the thrust or torque during micro drilling.

\section{Conclusions}

a) A micro drill as a connection with two equal cross section beams is developed, micro drills are in a compounding stress state which has the compress stress, the shear stress, the bending stress.

b) High stress concentrations occurring along the cutting edge, chisel edge, spiral element and spiral root are shown, the breakage mechanism are discusses based on these results of FEA, and some typical breakage pictures from many experiments fully proved them. 
c) The simulative results show that the maximum thrust and torque improve with an increase in the micro drills' diameter, loading the radial force increases the stress in micro drills, and decreases the lives of micro drills.

d) Experiment results show that the thrust and torque may be as the monitoring signals to forecast the micro drills' wear state.

\section{Acknowledgement}

In this paper, I would like to thank all my colleagues who participated in the experiment and the research of the subject.

\section{References}

1. Z.J.Yang, X.Li, Q.X.Jia. Development of a rough set-based fuzzy neural network for online monitoring of microdrilling. Int J Adv Manuf Technol, 41(2007)219-225

2. Y.C.Pei, Q.C.Tan and Z.J.Yang. A study of dynamic stresses in micro-drills under high-speed machining. International Journal of Machine Tools \& Manufacture,46(2006)1892-1900

3. L.P.Wang, Z.J.Yang, L.J.Wang Investigations on the Transverse Micro Drill Deflection of the Drill Point at the Entrance in Low Frequency Vibration Drilling, J.China Mechanical Engineering, 9(1998)pp59-62 (In Chinese)

4. Z.H.Shan. Material Mechanics(Edition 3)(II).Beijing: High Education Press,2010 (In Chinese)

5. M. M.TRAORE, Y.C.Pei, Q.C.Tan. Dynamic Stress Characteristic of High speed Micro hole Drill,J. Journal of Jilin University (Engineering and Technology Edition), 35(2005) 606-611

6. Y.H.Zhou, H.Guo, Q.He. The study of drilling process based on finite elemnet method,J.Natural Science Journal of Xiangtan University, 1(2012) 108-112 (In Chinese)

7. T.Dong, Y.G.Ren. Finite element simulation analysis of twist drill machining process. Mechanical Research \& Application, 118(2012) 47-50 (In Chinese)

8. J.S.Strenkowski, C.C.Hsieh, A.J.Shih, An analytical finite element technique for predicting thrust force and torque in drilling, International Journal of Machine Tools\& Manufacture44(2004)1413-1421. 